\section{Juniors' hours: is the end in sight?}

\author{
Fiona Godlee
}

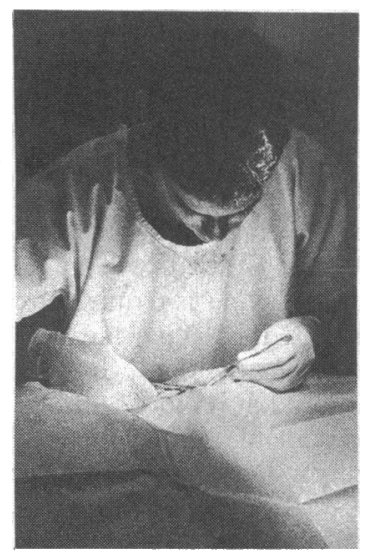

Summary

The question of how to reduce junior doctors' hours has taxed the government and hospital managers for nearly two decades. Now regional task forces are being asked to get them down to a maximum of 83 a week by 1 April next year. From a comparison of the way in which two different task forces (Northern and North West Thames) have responded to the challenge it emerges that most units will probably meet the 83 hour deadline by making simple rationalisations. Meeting the next deadline-of a 72 hour maximum by December 1996 - will, however, require radical restructuring of working patterns.

\section{The task forces' challenge}

Exhausted junior doctors could one day, like child labour and limited suffrage, be part of Britain's history. The new deal on juniors' hours, eventually hacked out between doctors' representatives, the royal colleges, and the Department of Health, set 1 April next year as the date beyond which no junior doctor should work more than 83 hours a week.' By 31 December 1996 all doctors should be working less than 72 hours. But, as members of the regional task forces set up to implement the new deal have been discovering, setting targets is one thing and meeting them quite another.

The term task force, with its Falklands war imagery, conjures up expectations of military precision and instant effect. In the context of juniors' hours, however, it denotes a small team of doctors and managerschaired by the regional director of public health and including the head of regional manpower, the postgraduate dean, a junior doctors' representative, and a representative from the royal colleges - with no direct power and few resources.

Working under tight financial constraints as well as the manpower ceilings imposed by Achieving $a$ Balance, ${ }^{2}$ the task forces cannot simply employ more juniors to pad out harsh rotas-though Trent's did just that and got away with it. ${ }^{3}$ The Department of Health has given them no direct guidance on how to proceed, the idea being that local difficulties will require individual solutions. Their brief is to gather data on current hours of work, to stimulate and monitor change by liaising with implementation groups in each unit, and to distribute a limited number of centrally allocated consultant and staff grade posts according to need.

So how effective are they being, and will they meet the 1 April deadline? Have junior doctors noticed any sign of change? To find out I visited two regions, Northern and North West Thames, and spoke to task force members and juniors.

British Medical Journal, Tavistock Square, London WC1H 9RJ

Fiona Godlee, assistant editor the only doctor to have been made a regional general manager in the new NHS and known for his ability to make things happen, the task force has been, in the words of one clinical director in the region, "terrier like in pursuing what it has to do."

From the start the task force took a high profile, making regular staged visits to each unit and gathering data on each post. The visits begin with a meeting with juniors' representatives, who, the task force hopes, speak freely about problems they are encountering. Other members of the local implementation groupa consultant, a medical staffing officer, a nursing administrator, and a manager - then join the meeting to discuss ways forward. Promises are extracted and, on subsequent visits, chased up.

Where things are slow to move the task forces can use both carrots and sticks to persuade and coerce. The carrots are the centrally funded consultant and staff grade posts, which are allocated to units that prove that they will use them to reduce juniors' hours. (So far 12 of the region's allowance of 25 consultant posts have been filled and six have been filled by locums pending permanent appointments.)

The sticks are the threats to withdraw approval for any post not coming into line. Use of such threats is however, limited. Regions have control over registra and senior registrar posts, which they can therefore refuse to advertise. They also control approval of preregistration posts through their regional postgraduate deans. But they have no jurisdiction over senior house officer posts. Dr Deborah Richardson Kelly, director of medical manpower in Northern region, would like to see senior house officer posts brought under the regional umbrella.

Liam Donaldson is also happy to make use of pee pressure and competition. Overriding the cynics by highlighting the achievements of the enthusiasts is, he says, the way to change attitudes. He draws parallels with other changes in the NHS. Getting the waiting list initiative accepted was, he says, a question of winning hearts and minds plus "a little bit of peer pressure to break the log jam."

But perhaps the, most immediate incentive to reduce hours of duty in all regions is the recent introduction of the new pay scales for juniors. Having to pay additiona hours of duty at $50 \%, 70 \%$, and $100 \%$ of the basic rate for on call, partial shifts, and full shifts respectively has concentrated the minds of managers wonderfully. The wage bill in the Northern region for 1992-3 has gone up by $£ 6-8 \mathrm{~m}$, an increase of $18 \%$ since $1991-2$, while funding from the Department of Health rose by only $5 \cdot 5 \%$.

This bill will, of course, gradually fall as juniors on protected salaries move on and new contracts are signed for fewer hours. Meanwhile, however, hospitals are under financial pressure. The Freeman Hospital, a self governing teaching hospital trust in Newcastle, is faced with an extra $£ 0.5 \mathrm{~m}$ to pay for juniors' wages. Managers there have reduced the contracted additional duty hours of the new intake of medical senior house 
officers from 40 to 36 without changing the rota from a one in four with prospective cover. They have done this by cutting each doctor's annual study leave allowance from the discretionary 30 days set down in the Whitley Council guidelines to a maximum of 10 . The move has outraged juniors at the hospital. "It calls itself a teaching hospital," said one, "and yet its main solution to the hours problem is to cut study leave."

Dr Ian Griffiths, consultant rheumatologist and clinical director of medical services at the Freeman Hospital, defended the decision. It was either that, he said, or redundancies elsewhere. "We are a worried hospital in terms of how we are going to balance the books and still maintain the service. Given all the constraints under which we are having to function, the 10 day limit on study leave is, I think, fair and reasonable."

The anger of juniors at the Freeman Hospital seems to stem largely from poor communication with management. Not being paid on time because of a mix up with the regional pay roll-now rectified, says Dr Griffiths-would have been less worrying, said one junior, if the medical staffing department had simply explained the situation. Juniors at the hospital have asked for one manager to be their point of contact with the hospital administration, but so far nothing has happened.

\section{Unreliable data on hours and posts}

One of the main difficulties reported by all the task forces is getting accurate data about both the number of posts and the number of hours worked. Sources of this information include the pay roll-recently devolved from region to district level; medical staffing records; and junior doctors' representatives. The problem, says David Lewis, task force information officer for the Northern region, is that each source can give "radically different" figures. With each six monthly set of data sent to the department (table I) the total number of junior posts analysed changes in ways that cannot be attributed to actual changes in appointments. "More posts are found every time," says Michael Varley, medical manpower manager for North West Thames region.

To check that contracted hours bear some relation to actual hours worked the task forces rely heavily on links with junior doctors in each hospital, links that have to be reformed every six months as juniors move on to other jobs. Getting juniors to attend meetings is another problem: despite high level injunctions to allow them time off to attend many have found it

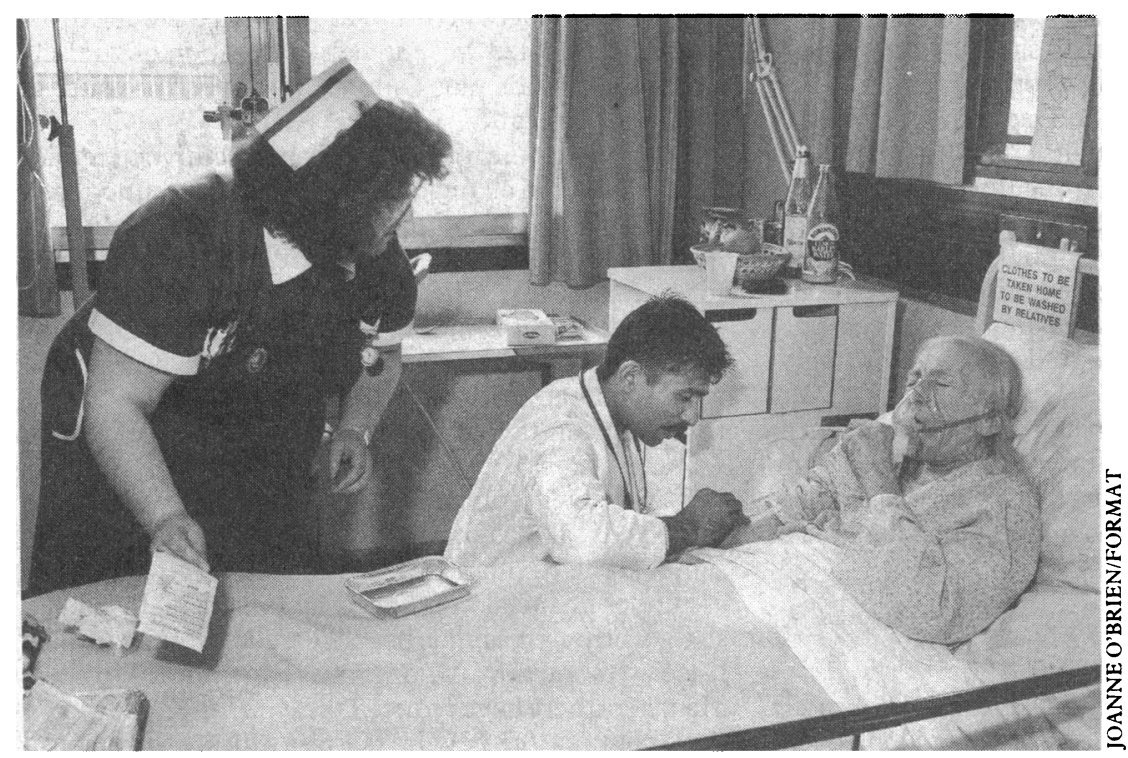

TABLE I-Changes in hours worked by all training grades since September 1991, Northern and North West Thames regions (figures are numbers (percentages) of doctors)

\begin{tabular}{|c|c|c|c|}
\hline Hours worked & $\begin{array}{c}\text { September } \\
1991\end{array}$ & $\begin{array}{c}\text { February } \\
1992\end{array}$ & $\begin{array}{l}\text { August } \\
1992\end{array}$ \\
\hline \multicolumn{4}{|c|}{ Northern region } \\
\hline$>83$ & $373(23)$ & $250(16)$ & $164(10)$ \\
\hline $72-83$ & $694(43)$ & $788(50)$ & $867(52)$ \\
\hline$<72$ & $555(34)$ & $545(34)$ & $630(38)$ \\
\hline Total & $1622(100)$ & $1583(100)$ & $1661(100)$ \\
\hline \multicolumn{4}{|c|}{ North West Thames } \\
\hline$>83$ & N/A & $475(20)$ & $682(29)$ \\
\hline $72-83$ & N/A & $1451(60)$ & $681(29)$ \\
\hline$<72$ & N/A & $487(20)$ & $980(42)$ \\
\hline Total & N/A & $2413(100)$ & $2343(100)$ \\
\hline
\end{tabular}

difficult, and three whom I spoke to had suffered intimidation from consultants, nursing officers, or managers.

Intimidation is the extreme end of a range of disincentives to juniors getting involved in the changes. At the other end is the fear that consultants will frown on juniors taking time off in the day, as is required by some partial shifts, or filling in the Department of Health's claim forms for extra hours worked. (In fact, in most of the hospitals I inquired at juniors said that the necessary forms were not available.)

Despite these problems Liam Donaldson is confident that all hospitals in the Northern region will meet the 1 April deadline. They have already reduced the number of juniors working over 83 hours from 373 this time last year to 164 now.

\section{London's special problems}

The chairman of North West Thames regional task force, Dr Angela Jones, is less optimistic abou meeting the deadline. Data from the region's returns to the Department of Health suggest that the number of juniors working more than 83 hours a week has actually increased since February from 475 to 682 . (This is probably because data collected over the past six months has been more accurate with regard to hours worked.) There have also been delays in appointing people to the new posts (only five of the region's centra allowance of 23 consultant posts have been filled with permanent appointments). But the North West Thames task force pleads some special problems. O the region's 23 units, over half are self governing trusts, which normally operate outside regional control, and seven are on split sites. Two are major teaching hospitals-St Mary's and Charing Cross/ Westminster-with their often entrenched medical hierarchies, and three are special health authorities, which with their superspecialist units are not ideally suited to extensive cross cover arrangements.

The Royal Marsden and Brompton Hospitals are high on the list of those with intractable problems, with specialist senior registrars on one in one rotas. Doctors there are worried that cross cover would mean inappropriate doctors looking after sick patients, something that they argue would not be in the interests of either patients' quality of care or doctors' training. At Harefield Hospital, where heart and heart lung transplant operations make up much of the workload, 22 of the 33 junior posts are still over the 83 hour limit

But with the abundance of junior doctors in London - two to every one consultant compared with $1 \cdot 2$ to 1 in the Northern region - it would be a surprise if North West Thames had not achieved some considerable reductions. Hammersmith Hospital is one success story. Effectively a district general hospital with a clinical research centre attached, it has many junior staff on a single site - perfect fodder for rationalisation. 


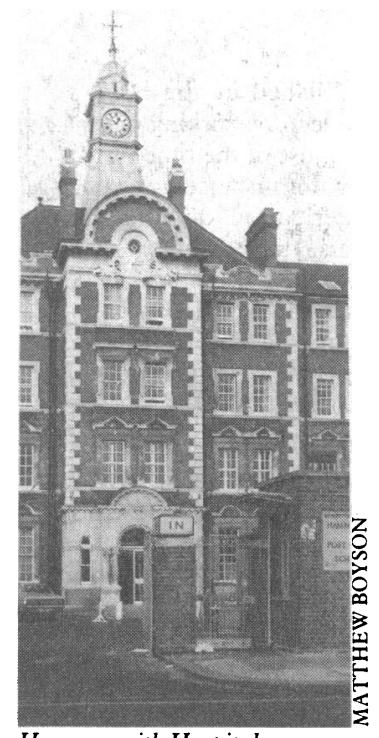

Hammersmith Hospitalheading straight for the 72 hour deadline
Its implementation group decided to go straight for the second deadline rather than go through the disruption of reorganising rotas twice, and it looks set to get there by 1 April. "It's clear that we are grossly overstaffed at all levels in relation to the number of patients," said Dr Kevin Davies, senior registrar in rheumatology and the hospital's resident medical officer, "so it has been much easier for us to get the hours of direct clinical responsibility down." The hospital has also been able to call on research registrars to cover the cracks in the paediatrics rota, the specialty that has presented huge manpower problems elsewhere.

Kevin Davies has his doubts about using research staff in this way. "Apart from the question of whether it is right to take people away from their MDs, it's risky to include them in your long term master plan when they are funded by soft money which may be withdrawn at any time."

Like other regions in London, North West Thames also has to contend with the uncertainty of what the Tomlinson report will contain. This, says $\mathrm{Dr}$ Jones, has produced a siege mentality among many consultants and managers in the capital. "There are so many different agendas in the Thames regions at the moment," she said. "It's difficult to enforce too many changes on people."

\section{Working conditions}

Other means of reducing hours-such as introducing phlebotomy services and additional ward clerks - have been taken up in most units - though in some cases all they have done is show up the doctors' jobs for what they are. "It was clear that I had just been a blood taking machine," said one house officer in the Northern region. "When the phlebotomist arrived I found I had nothing useful to do."

Concern about the high service element and low educational content of juniors' jobs was highlighted by the report on inappropriate tasks from London University and was taken up with good effect by the colleges and postgraduate deans. But the question of who should take on these tasks remained delicate; talk of "handing down inappropriate tasks" caused understandable offence among nurses. Local policies controlling what nurses could and could not do caused frustration among juniors and nurses. Nurses who had happily given intravenous drugs at other hospitals had to be certified at their new hospital, and courses for certification were invariably oversubscribed.

An apparently timely decision from the nurses' controlling body, the United Kingdom Central Committee of Nursing, to change its ruling about nurses performing certain clinical tasks seems to have answered the problem. It now allows each nurse to decide whether he or she feels competent to do the task, whether it be giving an intravenous drug, diagnosing death, performing electrocardiography, or defibrillating a patient, rather than demanding certification from the district nursing committee. (The committee is, however, anxious to make it clear that its decision was not made to accommodate the changes in junior doctors' hours.)

TABLE II -Summary of controls on hours *

\begin{tabular}{|c|c|c|c|c|c|}
\hline \multirow{2}{*}{$\begin{array}{l}\text { Working } \\
\text { arrangements }\end{array}$} & \multicolumn{2}{|c|}{$\begin{array}{l}\text { Maximum contracted } \\
\text { hours per week }\end{array}$} & \multirow{2}{*}{$\begin{array}{c}\text { Maximum } \\
\text { continuous duty }\end{array}$} & \multirow{2}{*}{$\begin{array}{l}\text { Minimum } \\
\text { period off duty } \\
\text { between duty } \\
\text { periods }\end{array}$} & \multirow{2}{*}{$\begin{array}{c}\text { Minimum } \\
\text { continuous } \\
\text { period off duty }\end{array}$} \\
\hline & $\begin{array}{l}\text { As soon as } \\
\text { practicable }\end{array}$ & By 31 Dec 1994 & & & \\
\hline Full shift & 60 & 56 & 14 & 8 & $48+62$ in 28 days \\
\hline Partial shift & 72 & 64 & 16 & 8 & $48+62$ in 28 days \\
\hline \multirow{2}{*}{ On call rota } & 83 & 72 & 32 & 12 & $48+62$ in 21 days \\
\hline & & $\begin{array}{c}\text { (for hard pressed } \\
\text { posts) }\end{array}$ & (56 at weekends) & & \\
\hline
\end{tabular}

$\star$ Reproduced from ref 4
Problems still remain. The changes have potentially enormous resource implications for nurses-the nursing administration at the Freeman Hospital has asked for $£ 35000$ for employing extra nursing staff to give intravenous drugs. Gillian Moyse, the Northern region's nursing practice facilitator, believes that nurses could make room for more clinical tasks by offloading clerical work on to ward clerks. She is certain that getting nurses to give intravenous drugs will not save money, but it will, she says, improve the service to patients because more of these drugs are given on time if nurses on each ward can give them. It is this patient centred approach that has, she says, turned confrontation between doctors and nurses into a more fruitful dialogue about shared care.

By setting up meetings in units around the region Gillian Moyse hopes to disseminate examples of good practice. In some hospitals all out of hours calls from nurses to junior doctors are filtered by the night coordinator, who deals with some and saves up the others to limit calls to the doctors' bleeps. In North Tees the stroke unit has introduced collaborative care planning, whereby one set of notes is used by all the health care professionals involved in a patient's care. South Tees Hospital is looking at the possibility of a joint training programme for nursing sisters and junior doctors and developing management protocols that would be common to medical and nursing staff.

\section{Consultants digging in}

Consultants get a varied press from the task forces and the juniors. Some have been cooperative, others have apparently dug in their heels to the last. Those in teaching hospitals remain largely wedded to the firm structure, each with its own set of junior staff. Professor Elizabeth Shore, regional postgraduate dean in North West Thames, was amazed at how few departments took advantage of the offer of a fully funded additional consultant post. They tended instead to ask for a staff grade post, justifying it by saying they had "a full complement of consultants." "It's the culture of the gentlemen's club," she said.

But increasing consultant numbers is firmly enshrined in Achieving a Balance, alongside the need to develop a consultant led service. This will mean reversing the ratios of consultants to junior doctors so that consultants are working with fewer tiers of training grade staff. Consultants are understandably worried about this prospect, but Liam Donaldson believes that it will not necessarily mean increasing their workload. "It should not mean more work for consultants, just different work," he said.

New consultants appointed through the new deal or Achieving a Balance should be "activity neutral." This means they should take on work now being done by juniors, such as clinics and ward work, rather than attract new referrals. Consultant posts funded by the junior doctors' initiative must have an impact on juniors' hours otherwise central funding will be withdrawn.

Other changes may help to dismantle the traditional firm structure. Acceptance of the recommendations of the chief medical officer's working party on accreditation and specialisation in Europe would allow specialists-equivalent to accredited senior registrars - to function independently within a flatter career structure rather than report up to consultant staff.

\section{Living conditions}

The task forces are also responsible for seeing that juniors' living conditions are improved. Small domestic details can make or break relations between juniors and hospital administrators, and hospitals in 
both regions are still failing to provide simple things like the possibility of phoning home, change for the vending machine, and a hot meal in the evening - that make life bearable for juniors trapped in a hospital over a long weekend. At the Freeman Hospital repeated complaints from juniors have met with little response from managers. Ian Griffiths admitted that over the past six months relations had reached an all time low. Juniors calling the duty administrator at 2 am to ask for the sheets on the on call bed to be changed had done nothing to ease matters.

Improvements in both working and living conditions have been funded from task force money not spent on additional consultant and staff grade salaries because of delays in filling the new posts. So far the Northern regional task force has used $£ 438000$, half on appointing phlebotomists and ward clerks and half on upgrading accommodation and mess facilities.

Last year in North West Thames units that were allocated additional staff were immediately handed the money to pay their salaries regardless of whether an appointment had been made. As a result these units ended up with extra cash to spend regardless of the state of their juniors' living conditions. This year the task force has retained control over unspent money - now standing at about $£ 287000$ - and plans to distribute it next month, concentrating on those units most in need. This means that it can wait to hear the conclusions of the Tomlinson report. "It would be foolish," says Michael Varley, "to hand over money for upgrading accommodation and equipment to units that may soon be closing."

The mess at Ashford Hospital received $£ 10000$ in the first payout. As it happened, it was in dire need of upgrading; on an earlier visit task force representatives fused the electricity supply by turning on the cooker. But Dr Andrew Carney, junior doctors' representative for North West Thames, questions the appropriateness of using task force money to pay for what is essentially routine maintenance. "It's amazing," he said, "that this basic estate management work has to be funded in this way."

Perhaps more galling for the task forces is the tendency for units to upgrade accommodation and appoint support staff and not make it clear to the juniors where the money has come from. "It's important that we get the credit," said Angela Jones, especially since it is the visible changes, like carpets in the mess and phlebotomists on the wards, that impinge most on juniors. "Morale goes up when they see concrete evidence of change," said a juniors' representative at Queen Elizabeth Hospital in Gateshead. "No amount of talking makes any difference."

\section{Getting down to 72 hours}

Badgered by financial pressures and task force deadlines, most units will get to grips with the 83 hour limit, though some will miss the April deadline. But this has largely been achieved by obvious rationalisations. Getting down to 72 hours will not be possible without much more radical change. Liam Donaldson believes that the only way ahead is through the creation of many more staff grade posts - the Northern region is already up against the centrally agreed limit of $10 \%$ of consultant numbers-and much wider adoption of partial shifts.

At present only one partial shift is in operation in the Northern region, and Andrew Carney knows of "only a handful" in his region. The reason seems to be twofold. Firstly, juniors fear that partial shifts will mean greater disruption of their time off and reduced educational input because of the need to take time off in the day. Secondly, no one seems quite clear what partial shifts are. The new deal defines rotas and shifts

\section{What is a partial shift?}

Booklet on the new deal published by the BMA's junior doctors' committee. ${ }^{+}$Doctors working partial shifts work normal weekdays most of the time but at intervals work a different duty, for instance a week on nights every fourth week. Periods of duty can be longer than for full shifts because the work is expected to be less intensive. Doctors on duty will normally be called to see patients in various wards or departments of the hospital and, in addition to natural breaks, should be able to take short rests (at least four hours of rest during every duty period of 16 hours)

Michael Varley: Partial shifts are defined by exclusion. They are any working pattern that is not a rota or shift work.

Junior doctor in Sunderland: I don't know.

Andrew Carney: On a full shift you expect to be working all the time you are on duty (as in casualty), a fact that is reflected in the payment of $100 \%$ rates for hours worked. On a rota you should have a reasonable expectation of six hours' uninterrupted sleep after midnight, which justifies the payment for hours of duty over the basic 40 hour week at $50 \%$ of the full hourly rate. On a partial shift you are neither working flat out nor are you likely to get uninterrupted sleep, and so additional duty hours are paid at $70 \%$ the full hourly rate. Partial shifts usually involve time off in the day, split weekends, and fixed holidays.

but leaves the definition of partial shifts vague (box).

According to Andrew Carney, some junior doctors in North West Thames have been doing partial shifts but have been paid as though they are on rotas. Senior house officers working in one paediatric intensive care unit work for two weeks from 9 am to $5 \mathrm{pm}$ followed by two weeks of 24 hours on and 24 hours off duty. "It is a partial shift, though it breaches the 16 hour maximum for continuous duty, but the doctors are being told it is a rota and are being paid as such."

As for the members of the task forces, they could do with limits being set on their own hours. Most have taken on the task force work in addition to their full time jobs, and as the first deadline approaches many seem exhausted and overwhelmed. The Northern region has employed a full time information officer, a move that Deborah Richardson Kelly sees as having contributed to its success. "If something's really important you've got to have good people spending all their time on it," she said. "That's how you get things changed."

\section{Conclusion}

"Units have tackled all the problems that can be resolved easily," said Chris Finlan of the BMA's junior doctors' committee. "They are now up against the much more complex problems-split sites, radical changes in working patterns. Attempts to solve them will have wide ramifications for everyone, not just doctors." Angela Jones agrees. "We have to turn people's thinking around. We need to completely rethink the way we process patients through hospitals. Only when we have got doctors working in teams rather than the old style firms will we get the hours down. Cutting juniors' hours will, in the end, mean fundamental changes in working practices at all levels."

1 NHS Management Executive. Junior doctors. The new deal. London: NHS Management Executive, 1991.

2 UK Departments of Health, Joint Consultants Committee, and chairmen o regional health authorities. Hospital staff: achieving a balance. London: Department of Health and Social Security, 1986.

3 Limb M. Trent. First in the race against time. Health Services fourna 1992;102:33.

4 BMA Junior Doctors' Committee. Funior doctors. The new deal. London: BMA, 1991. 